\title{
Evaluation of Analytical Methods to Study Aquifer Properties with Pumping Tests in Coastal Aquifers with Numerical Modelling (Motril-Salobreña Aquifer)
}

\author{
M. L. Calvache ${ }^{1}$ - J. P. Sánchez-Úbeda ${ }^{1}$ - C. Duque ${ }^{2}$ • \\ M. López-Chicano ${ }^{1} \cdot$ B. de la Torre ${ }^{3}$
}

Received: 29 May 2015 / Accepted: 27 October 2015 /

Published online: 15 November 2015

C) The Author(s) 2015. This article is published with open access at Springerlink.com

\begin{abstract}
Two pumping tests were performed in the unconfined Motril-Salobreña detrital aquifer in a $250 \mathrm{~m}$-deep well $300 \mathrm{~m}$ from the coastline containing both freshwater and saltwater. It is an artesian well as it is in the discharge zone of this coastal aquifer. The two observation wells where the drawdowns are measured record the influence of tidal fluctuations, and the well lithological columns reveal high vertical heterogeneity in the aquifer. The Theis and Cooper-Jacob approaches give average transmissivity (T) and storage coefficient (S) values of $1460 \mathrm{~m}^{2} / \mathrm{d}$ and 0.027 , respectively. Other analytical solutions, modified to be more accurate in the boundary conditions found in coastal aquifers, provide similar $\mathrm{T}$ values to those found with the Theis and Cooper-Jacob methods, but give very different $S$ values or could not estimate them. Numerical modelling in a synthetic model was applied to analyse the sensitivity of the Theis and Cooper-Jacob approaches to the usual boundary conditions in coastal aquifers. The $\mathrm{T}$ and $\mathrm{S}$ values calculated from the numerical modelling drawdowns indicate that the regional flow, variable pumping flows, and tidal effect produce an error of under $10 \%$ compared to results obtained with classic methods. Fluids of different density (freshwater and saltwater) cause an error of $20 \%$ in estimating T and of over $100 \%$ in calculating S. The factor most affecting $\mathrm{T}$ and $\mathrm{S}$ results in the pumping test interpretation is vertical heterogeneity in sediments, which can produce errors of over $100 \%$ in both parameters.
\end{abstract}

Keywords Pumping test - Costal aquifer V Vertical heterogeneity - Theis solution · Cooper-Jacob solution · Numerical modelling

M. L. Calvache

calvache@ugr.es

1 Departamento de Geodinámica, Universidad de Granada, 18071 Granada, Spain

2 Department of Geosciences, University of Oslo, Oslo, Norway

3 Departamento de Ecología y Geología, Universidad de Málaga, Málaga, Spain 


\section{Introduction}

Pumping tests are the most widely used method for estimating hydrogeological parameters such as transmissivity and storage coefficient in aquifers. The first analytical solutions for the equation of groundwater flow in aquifers subjected to pumping provided by Thiem (1906) for a steady state, and by Theis (1935) and Cooper and Jacob (1946) for a transient state, consider very restrictive conditions that limit their application to aquifers that are porous, uniform, homogeneous, infinite, of constant thickness and isotropic, and in which pumping occurs in a completely penetrating well with a constant discharge. Subsequent modifications to these initial analytical solutions have expanded the application conditions. Boulton (1954) pointed out the effect of delayed drainage in an unsaturated zone in an unconfined aquifer and Neuman $(1972 ; 1974)$ in partially penetrating unconfined aquifers. Hantush (1960) proposed a solution for the case of a leaky confined aquifer with storage in the aquitard and a variable rate. Hantush (1961) also offered a solution for the case of anisotropic aquifers and partially penetrating wells. Papadopulos and Cooper (1967) worked with large-diameter wells.

The interpretation of pumping tests in coastal aquifers is highly complex since a number of specific conditions can influence the results. For instance, the co-existence of freshwater and saltwater produces changes in density, and tide-induced head fluctuations can complicate the interpretation of drawdown data from pumping tests (Trefry and Johnston, 1998; Sakr, 2001). Sakr (2001) proposes type-specific curves for aquifers with freshwater and saltwater. In addition, Chen and Jiao (1999) and Chapuis et al. (2006) propose correcting for tidal effects in the drawdown data for confined aquifers by subtracting the net tidal effects measured before pumping. Trefry and Johnston (1998) and Chattopadhyay et al. (2014) applied a least squares regression technique to attenuate tidal influence. Ni et al. (2011) propose applying the Cooper-Jacob method on the rectilinear stretch of the s-logt function based on the fact that tides cause regular fluctuations in groundwater of the same amplitude.

Another circumstance that may occur in a coastal aquifer is the existence of an artesian well (Calvache et al. 2011), resulting in a variable pump flow diminishing over time. Interpretations of pumping tests in artesian conditions for any type of aquifer (not necessarily coastal) have been specifically studied by Jacob and Lohman (1952) considering a variable well discharge but with constant drawdown. However, Sternberg (1967) presents an approximate solution for decreasing discharge. Lai et al. (1973) consider a variable discharge that is both linear and exponential. Sen and Altunkaynak (2004) compare the T and S values obtained considering steady and variable discharge, respectively. Zhang (2013) applies Theis' method and proposes a new type of curve for the case of variable discharge, validating the method with a numerical model, although it requires several measurements of drawdowns in different points at varying distances from the pumping point. Mishra et al. (2013) consider a sinusoidal variation of the discharge.

Detrital coastal aquifers are also often stratified sediments with alternating layers of extremely different hydraulic conductivity. The influence of vertical heterogeneity in the interpretation of pumping tests has concerned experts for some time. As noted by Hemker (1999), most analytical solutions for vertical heterogeneity consider the case of multiaquifer systems (Hemker 1985; Hemker and Maas 1987; Maas 1987b; Streltsova 1988). However, few analytical solutions allow for some sort of vertical heterogeneity within the aquifer. Maas (1987a) developed an analytical solution for vertical heterogeneity in steady-state conditions. Moench $(1995 ; 1996)$ uses analytical transient well flow solutions that include vertical flow components based on the numerical inversion technique of the Laplace transform solution. 
Hemker (1999) provides a solution of the general issue of computing well flow in vertically heterogeneous aquifers by integrating both analytical and numerical techniques. Alam and Olsthoorn (2014) use Hemker and Maas' (1987) numerical and analytical approaches to assess the benefits of using multidepth pumping tests in the analysis of deep layered and anisotropic aquifers. In most cases, a pumping test in aquifers with some vertical heterogeneity is resolved with numerical modelling (Hemker 1999; Riva et al. 2001; Kollet and Zlotnik 2005; Chen et al. 2014).

Despite these steps forward and the many modifications to the initial analytical solutions, there are still many unresolved limitations in interpreting pumping tests in coastal aquifers. Many studies on coastal aquifers consider it acceptable to use the $\mathrm{T}$ and $\mathrm{S}$ results obtained applying classic methods (Theis 1935; Cooper and Jacob 1946). Such is the case of Capuano and Jan (1996) and Vouillamoz et al. (2006), who apply the Theis and Cooper-Jacob solutions to a coastal detrital aquifer. Park et al. (2012) use Theis' solution for a fissured aquifer with freshwater and saltwater. Chachadi and Gawas (2012), Sabtan and Shehata (2003), Mohanty et al. (2012), and Lee et al. (2014) also apply Theis' solution in detrital coastal aquifers. Barlow et al. (1996) and $\mathrm{Ni}$ et al. (2011) noticed a tidal effect in their drawdown curves but did not consider it for evaluating T and S. Keith et al. (2006) and Mastrocicco et al. (2013) apply the Cooper-Jacob method to interpret pumping tests in detrital coastal aquifers. Diamantopoulou and Voudouris (2008) apply the Theis and the Cooper-Jacob methods to a multilayer coastal aquifer.

It can therefore be concluded that there are still uncertainties in the analytical solutions applied in interpreting pumping tests in coastal aquifers. In addition, the classic analytical solutions are applied even when the theoretical conditions required by those solutions are not met.

This study presents the case of two pumping tests carried out in a deep well penetrating the Motril-Salobreña coastal aquifer (southern Spain), which has a series of specific circumstances typical of coastal aquifers that make it difficult to interpret drawdowns from the pumping tests. It is an artesian well with a decreasing variable flow drilled in a detrital aquifer with a layered series having different hydraulic conductivity and with significant flow to the sea. In addition, the well intersects the freshwater-saltwater mixing zone and is affected by tidal fluctuations due to its proximity to the coastline. The main objective of this paper is to determine the error of the T and S values obtained applying the classic methods of Theis and of Cooper-Jacob due to these specific characteristics of coastal aquifers. This objective is approached with numerical modelling, which allows a quantification of the impact on the theoretical results.

\section{Study Area and Hydrogeological Setting}

The unconfined detrital Motril-Salobreña aquifer, located on the Mediterranean coast in southern Spain (Fig. 1), covers a surface area of $42 \mathrm{~km}^{2}$ and comprises alluvial sediments supplied by the Guadalfeo River and other minor streams. The aquifer's main recharge source is the Guadalfeo River, providing direct infiltration in the $8 \mathrm{~km}$ of its course over the aquifer and indirect infiltration from irrigation water deriving from the same river (Calvache et al. 2009; Duque et al. 2011).

The Motril-Salobreña aquifer is one of the few on the Spanish Mediterranean coastline that has of yet shown no signs of marine intrusion in contrast to the usual case for aquifers in semi-arid coastal zones (Kourakos and Mantoglou, 2011; Doulgeris and Zissis, 2014; Zekri 


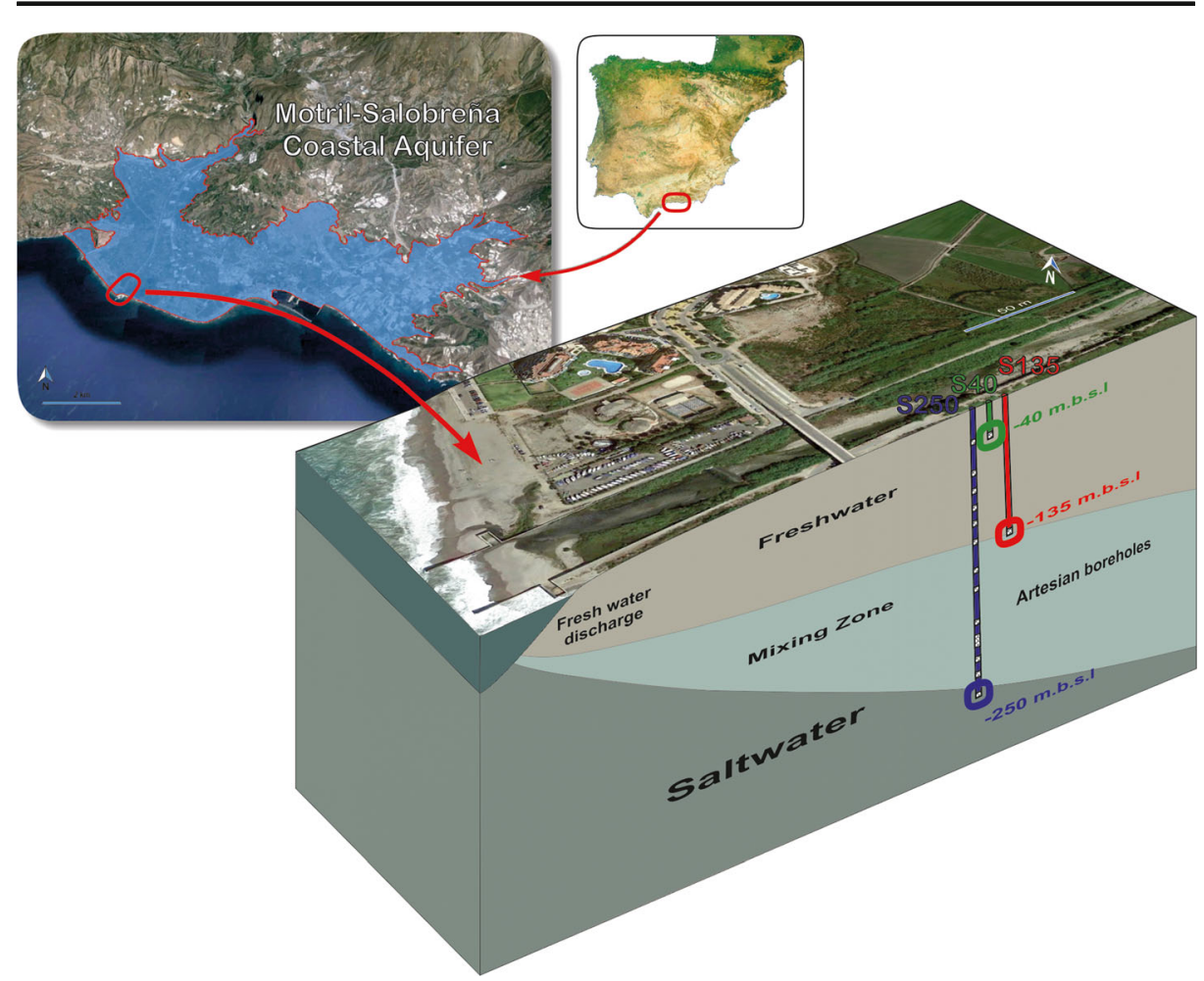

Fig. 1 Location of the study area and the pumping and observation wells

et al. 2015). Quite the contrary, it shows signs of very active freshwater discharge, as corroborated by the fact that the freshwater-saltwater contact does not penetrate far inland (Duque et al. 2008; Calvache et al. 2009).

At $300 \mathrm{~m}$ from the coastline, three wells were drilled clustered within a few metres of each other. The three are flowing artesian wells. The deepest (S250) is $250 \mathrm{~m}$ deep with 12 screens ( $3 \mathrm{~m}$ each) distributed along its length, supplying an average flow of $18 \mathrm{~L} / \mathrm{s}$. The other two wellbores are piezometers (4.7 and $9.6 \mathrm{~m}$ from the first well) with respective depths of $40 \mathrm{~m}$ (S40) and $135 \mathrm{~m}$ (S135). The average flow of these two monitoring wells is 0.10 and $0.13 \mathrm{~L} / \mathrm{s}$, respectively. The three wells are normally hermetically sealed to prevent uncontrolled discharge from the aquifer. Electrical conductivity logs from well S250 indicate that the saltwater-freshwater interface is approximately 135-200 m deep.

The artesian character of the three wells could be due to the typical flow pattern of discharge zones, with features of vertical flow and increasing head with depth. This discharge-zone flow pattern, typical of the freshwater-saltwater contact in a coastal aquifer (Glover 1959; Kohout 1964), is even more pronounced due to the fact that the Motril-Salobreña aquifer has a high horizontal hydraulic gradient, which in turn causes an increase in the vertical hydraulic gradient in the discharge zone (Calvache et al. 2011).

The lithological column in this sector of the aquifer can be roughly grouped into three units. From the surface down to $65 \mathrm{~m}$, the dominant lithology is fine sand with silty and scarce gravel layers. From $65 \mathrm{~m}$ down to $140 \mathrm{~m}$, there are centimetre-sized gravels mixed with coarse sand. From $140 \mathrm{~m}$ to the bottom $(250 \mathrm{~m})$, there are abundant clays with intercalating thin gravel 
layers. The latest studies on the aquifer, using numerical modelling calibration, provide average transmissivity and specific yield values of $5000 \mathrm{~m}^{2} / \mathrm{d}$ and 0.12 , respectively, not taking into account vertical changes (Duque 2009).

The hourly log of the heads of the two piezometers (S40 and S135) shows the effect of tidal fluctuations, particularly in monitoring well S135 (15 cm versus $5 \mathrm{~cm}$ in the shallower well) (Fig. 2).

\section{Methods}

The following steps were followed in the course of this work:

1. Two pumping tests were performed on artesian well S250 by keeping the well open and continuously measuring the drawdowns and recoveries in piezometers S40 and S135.

2. Estimate of $\mathrm{T}$ and $\mathrm{S}$ values by applying:

a. Classic methods (Theis and Cooper-Jacob) using the AQTSOLV software (Duffield 2007), which can consider a constant pumping flow or a variable discharge by applying Streltsova's (1988) principle of superposition.

b. Other analytical solutions considering certain variants on the boundary conditions examined in the classic methods. Specifically, the methods proposed by the following authors were applied: (1) Sakr (2001) for tests in coastal aquifers with freshwater-saltwater mixing zones. (2) Sen and Altunkaynak (2004) for tests with variable discharge. (3) Chapius et al. (2006) applying the method of subtracting the tidal fluctuation in drawdowns obtained in sectors near the coastline.

3. Evaluation of the reliability of the Theis and Cooper-Jacob analytical models using a synthetic numerical model. Specifically, the factors determined are the effect of the variable fluid density, the non-uniform radial flow due to a hydraulic gradient, the non-steady pumping flow, regular fluctuations in the head on one of the boundaries,

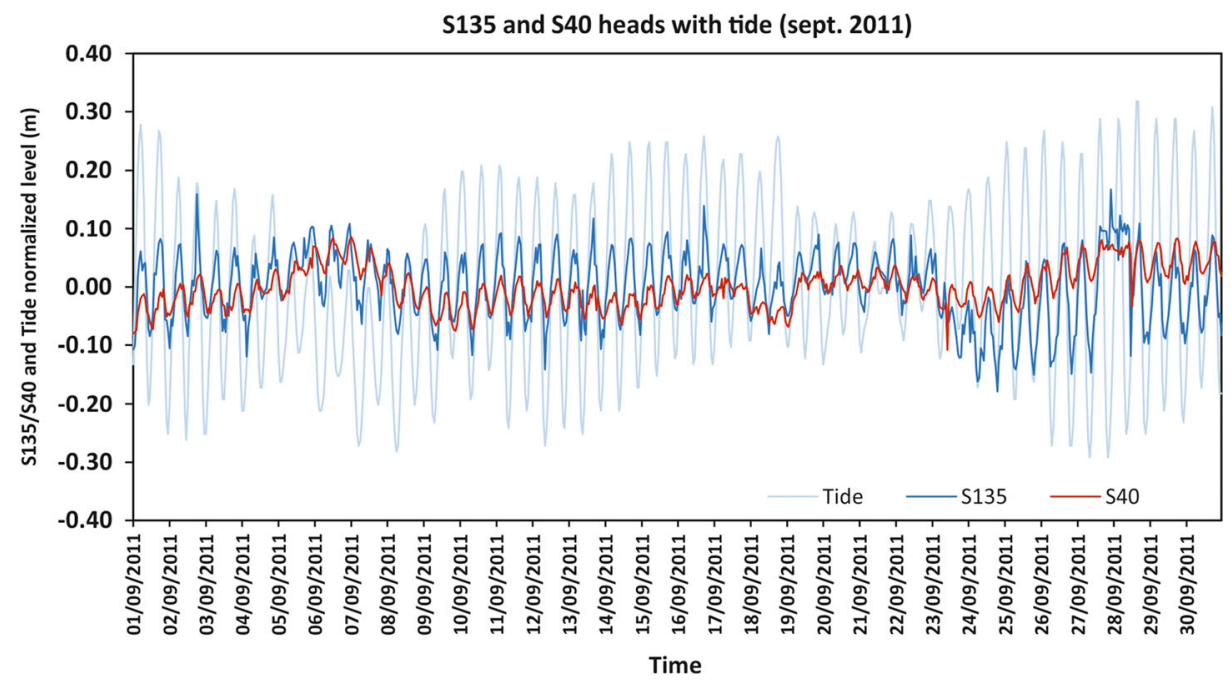

Fig. 2 Mediterranean tide and tidal effects in piezometers S40 and S135 
and the vertical heterogeneity of the hydraulic conductivity. The conceptual model considered is a simplification of the real study case since the objective is to determine the margin of error that the $\mathrm{T}$ and $\mathrm{S}$ values obtained with the classic methods can have when the boundary conditions considered by Theis and Cooper-Jacob are not met (case 1). To do so, the $\mathrm{T}$ and $\mathrm{S}$ values $\left(\mathrm{T}_{\mathrm{i}}, \mathrm{S}_{\mathrm{i}}\right)$ are estimated from the drawdowns for each simulated scenario, and the error with regard to case $1\left(\mathrm{~T}_{\mathrm{i}}, \mathrm{S}_{\mathrm{i}}\right)$ is calculated as

$$
\text { Error } r_{T}=\frac{T_{i}-T_{1}}{T_{1}} ; \text { Erro } r_{S}=\frac{S_{i}-S_{1}}{S_{1}}
$$

\subsection{Pumping Tests Description}

Two pumping tests were performed consisting in measuring the heads in the monitoring wells S40 and S135 after a prolonged opening of well S250. In the first test (PT1), well S250 was kept open for $23 \mathrm{~h}$ and $35 \mathrm{~min}$, allowing a recovery time of $3 \mathrm{~h}$ and $30 \mathrm{~min}$ after well S250 was sealed. In the second test (PT2), well S250 was opened for $26 \mathrm{~h}$ and $7 \mathrm{~min}$, allowing a recovery time of $23 \mathrm{~h}$ and $43 \mathrm{~min}$ (Table 1).

Throughout the two tests, the well discharge was measured at variable intervals, noting a progressive drop in flow. In PT1, discharge was between 20 and $16.7 \mathrm{~L} / \mathrm{s}$ and in PT2 it was 17.7 to $16 \mathrm{~L} / \mathrm{s}$. The average discharge for the two tests was taken as 18.2 and $16.8 \mathrm{~L} / \mathrm{s}$, respectively (Table 2).

In PT1, although the recovery time allowed was very short (3.5 h), the static water level was nearly reached, with a residual decrease of just $0.01 \mathrm{~m}$ in S40. In PT2, the recovery time was longer (almost $24 \mathrm{~h}$ ), allowing complete recovery of the water level.

In both tests, the effect of tidal fluctuations is noted, although it is much more noticeable in S135 than in S40.

\subsection{Numerical Modelling}

A finite-difference 3D model (SEAWAT) has been developed simulating a theoretical pumping test where the boundary conditions were modified in a total of seven different cases: (1) Theis and Cooper-Jacob conditions, (2) with a hydraulic gradient on the $\mathrm{X}$ axis, (3) with a variable pumping rate, (4) with a boundary with tidal fluctuations, (5) with vertical heterogeneity, (6) with fluids of different density (freshwater and saltwater), and (7) with all the above conditions. The size of the model is large enough to ensure a completely theoretical pumping, in which there is no border impact on the shape of the drawdown cones.

Table 1 Procedure of the two pumping tests carried out in the S250 well

\begin{tabular}{llll}
\hline Pumping Test 1 (PT1) & Pumping Test 2 (PT2) \\
\hline S250 well opening (PT start) & 1-11-11 12:30 & S250 well opening (PT start) & 21-2-12 10:20 \\
S250 well closing (PT end) & $2-11-11$ 12:05 & S250 well closing (PT end) & 22-2-12 12:27 \\
Recovering end & $2-11-11$ 15:35 & Recovering end & 23-2-12 12:10 \\
\hline
\end{tabular}


Table 2 Some pumping test data related to the pumping and observation wells

\begin{tabular}{|c|c|c|c|c|c|c|}
\hline \multirow[b]{2}{*}{ Observation point } & \multicolumn{2}{|l|}{ PT1 } & \multicolumn{4}{|l|}{ PT2 } \\
\hline & $\mathrm{S} 40$ & S135 & $\mathrm{S} 40$ & S135 & $\mathrm{S} 40$ recovering & S135 recovering \\
\hline Discharge $\left(\mathrm{m}^{3} / \mathrm{d}\right)$ & 1576 & & 1451 & & & \\
\hline Distance to pumping (m) & 4.72 & 9.60 & 4.72 & 9.60 & 4.72 & 9.60 \\
\hline Static Head (m) & 5.23 & 6.62 & 4.88 & 6.58 & 4.88 & 6.58 \\
\hline Max. Drawdown (m) & 0.79 & 0.45 & 0.49 & 0.44 & & \\
\hline Tidal-induced amplitude (m) & 0.008 & 0.06 & 0.006 & 0.06 & 0.028 & 0.09 \\
\hline
\end{tabular}

Accordingly, the model dimension (Fig. 3) was set to $5 \mathrm{~km}$ long (X dimension) by $5 \mathrm{~km}$ wide (Y dimension) by $200 \mathrm{~m}$ deep ( $\mathrm{Z}$ dimension), considering the ground surface at $3 \mathrm{~m}$ above sea level. Cells are $50 \mathrm{~m} \times 50 \mathrm{~m}$ and of variable depth in accordance with the two main situations: one layer (cases 1, 2, 3, 4, and 6) as a homogeneous aquifer and three layers (cases 5 and 7) to include heterogeneity in the aquifer (Fig. 3).

The main features for each scenario are listed in Table 3. The gradient defined between the two constant head boundaries is 0.001 in cases 2 and 7 . The tide condition imposed in cases 4 and 7 is described as a constant sinusoidal oscillation head boundary condition (Fig. 3B) on the left border from 0 to $1 \mathrm{~km}$, with the aim to produce a detectable disturbance in the records of the head observation wells. The expression used to define the tide oscillation is:

$$
H=A^{*} \sin \left(\frac{2 \pi}{T} *_{\mathrm{t}}-\varphi\right)
$$

where $H$ is the tide elevation [L], $A$ is the semi-amplitude of the tide [L], $T$ is the period of tide oscillation [T], $t$ is the time [T], and $\varphi$ is the phase of the tide $\left[{ }^{\circ}\right]$. In this case, tidal values similar to those in the Mediterranean Sea were considered. The semi-diurnal tide fluctuation for a 24-h period has been adjusted, with an amplitude of $2 \mathrm{~m}$, a frequency of $0.082 \mathrm{cycles} / \mathrm{h}$, and a period of $12.2 \mathrm{~h}$. Another variation (applied in cases 6 and 7) is added with the aim of evaluating the implication of variable density on the simulated pumping test. The considered density values are $0.35 \mathrm{~g} / \mathrm{L}$ (freshwater) and $35 \mathrm{~g} / \mathrm{L}$ (saltwater). A $10 \mathrm{~m}$-thick layer in the lowest level was considered, with a constant salinity of $35 \mathrm{~g} / \mathrm{L}$.

The pumping well is situated in the centre of the model domain $\left(2.5 \times 2.5 \mathrm{~km}^{2}\right)$, and fully penetrating, from $3 \mathrm{~m}$ to $-200 \mathrm{~m}$ depth (along the $\mathrm{Z}$ axis). The casing of the pumping well was assigned as fully screened. The variable pumping rate in cases 3 and 7 has been imposed with a linear decrease from $1600 \mathrm{~m}^{3} / \mathrm{d}$ to $1500 \mathrm{~m}^{3} / \mathrm{d}$, throughout one day of pumping. In other cases, the pumping rate is constant and equal to $1500 \mathrm{~m}^{3} / \mathrm{d}$.

Finally, eight head observation points were added in order to assess the symmetry of the drawdown cone produced by the pumping and the changes in heads with depth. They were distributed symmetrically on both the right and left sides of the well (R1-RS1-L1-LS1 $50 \mathrm{~m}$ and R2-RS2-L2-LS2 $100 \mathrm{~m}$ from the pumping well, respectively), as shown in Fig. 3B. The depths of the head observation points are:

- RS1, RS2, LS1, and LS2: - $5 \mathrm{~m}$ (below top of the model)

- R1 and L1: - $40 \mathrm{~m}$ (below top of the model)

- $\quad$ R2 and L2: - $135 \mathrm{~m}$ (below top of the model) 

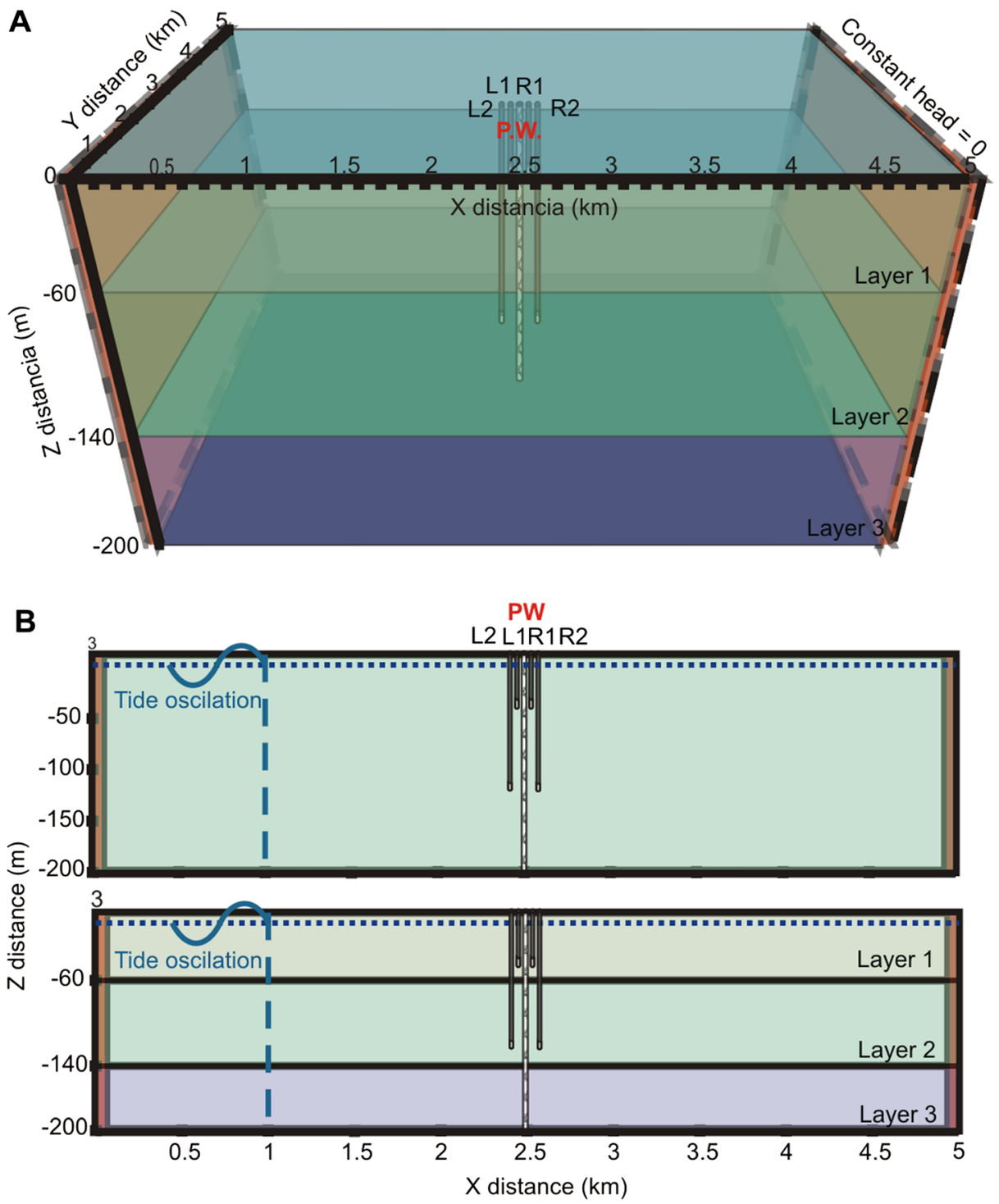

Fig. 3 Conceptual model scheme. a 3-D; b 2-D cross-section along a row in homogeneous (cases 1, 2, 3, 4, and 6) and heterogeneous cases (cases 5 and 7)

\section{Results}

\subsection{Pumping Test Interpretation}

For the estimation of $\mathrm{T}$ and $\mathrm{S}$, the drawdowns obtained in the two pumping tests (PT1 and PT2) in the Motril-Salobreña aquifer are used. The drawdowns in the two piezometers are slightly different in PT1 and PT2 due to the different discharge rates. However, in both tests S40 has higher drawdowns than S135 (Fig. 5) due to its greater proximity to the pumping and 


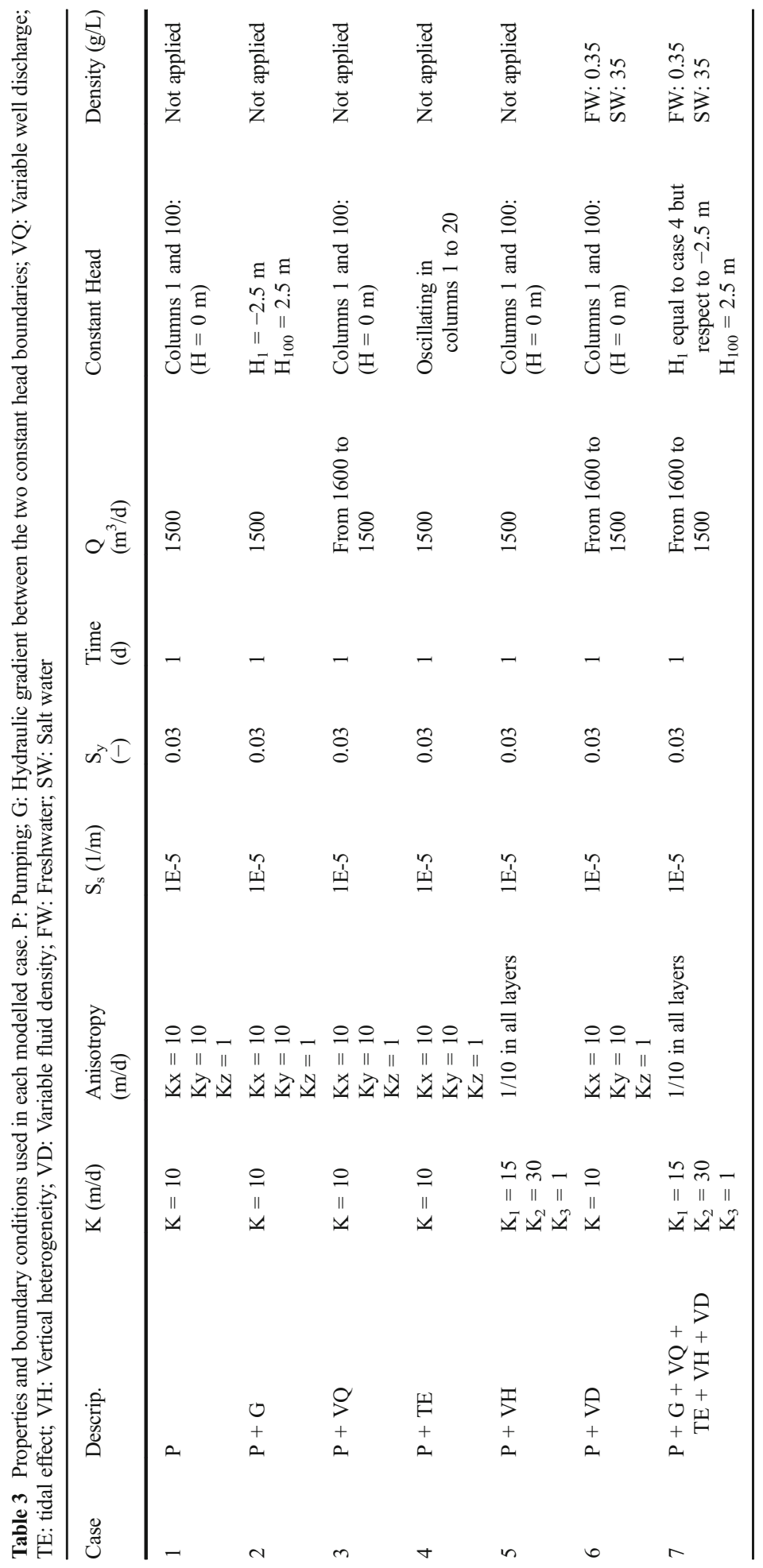


to the shallower measurement. The highest drawdown in S40 during PT1 was $0.79 \mathrm{~m}$ and 0.49 during PT2 (Table 2). In the case of S135, the differences in drawdowns are slight in both tests, never exceeding $0.02 \mathrm{~m}$.

In both tests, only diurnal and semi-diurnal tidal fluctuations are noticeable, with periods of around $24 \mathrm{~h}$ and $12.2 \mathrm{~h}$ respectively.

It can be seen that the flow around the pumping point interacts with the tidal effect of the levels. In fact, the fluctuations in S40 and S135 in the absence of pumping are 0.05 and $0.15 \mathrm{~m}$, respectively. However, during pumping they seem to be attenuated, logging 0.008 and $0.06 \mathrm{~m}$, respectively.

\subsubsection{Classic Methods}

The fit of the drawdowns to the theoretical curves was more satisfactory for well S40, with a standard error of $1.6 \%$ compared to $4 \%$ in the fit for S135. This difference is probably due to tidal fluctuations, which are much more evident in S135 and make the data difficult to fit (Fig. 4). The T data estimated for S40 and S135 range from 1598 to $2360 \mathrm{~m}^{2} / \mathrm{d}$ and 3192 to $4383 \mathrm{~m}^{2} / \mathrm{d}$, respectively. The $\mathrm{S}$ data range from 0.003 to 0.009 for $\mathrm{S} 40$ and $1.210^{-4}$ and 0.008 for S130.

Applying the modifications proposed by Streltsova (1988) for variable discharge, slightly lower $\mathrm{T}$ values than the above are obtained. These values range from 1292 to $1630 \mathrm{~m}^{2} / \mathrm{d}$ for S40 and from 2750 to $3249 \mathrm{~m}^{2} / \mathrm{d}$ for S135 (Table 4). However, for S the values are higher, with 0.023 for $\mathrm{S} 40$ and from 0.03 to 0.002 for S135. In general, the standard errors obtained when fitting the curves in the latter case are very similar to those not considering variable discharge. However, when variable discharge is considered, the fitted data logged in S40 show a minimum standard error $(1.5 \%)$. Therefore, the averages of estimates for S40 are taken as representative values for $\mathrm{T}$ and $\mathrm{S}$ in the western sector of the Motril-Salobreña aquifer applying the methods of Theis and Cooper-Jacob (with variable discharge). Specifically, a T of $1460 \mathrm{~m}^{2} / \mathrm{d}$ and an S of 0.027 are considered.

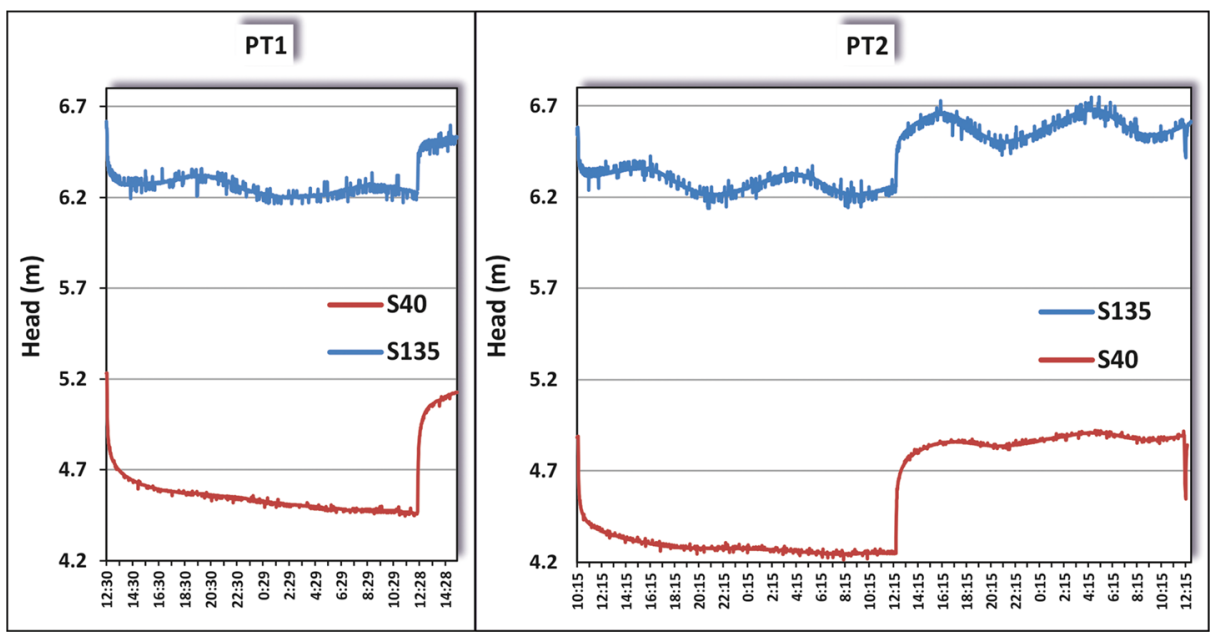

Fig. 4 Heads measured in S40 and S135 during pumping tests 
Table $4 \mathrm{~T}$ and $\mathrm{S}$ results obtained from classic methods

\begin{tabular}{|c|c|c|c|c|c|c|c|c|}
\hline & & & \multicolumn{2}{|l|}{ PT1 } & \multicolumn{4}{|l|}{ PT2 } \\
\hline & & & \multicolumn{2}{|l|}{ Pumping } & \multicolumn{2}{|l|}{ Pumping } & \multicolumn{2}{|l|}{ Recovery } \\
\hline & & & Cooper-Jacob & Theis & Cooper-Jacob & Theis & Cooper-Jacob & Theis \\
\hline \multirow[t]{4}{*}{ Constant Discharge } & $\mathrm{T}\left(\mathrm{m}^{2} / \mathrm{d}\right)$ & $\mathrm{S} 40$ & 1602 & 1598 & 1977 & 1971 & 2360 & 1933 \\
\hline & & $\mathrm{S} 135$ & 4381 & 4383 & 3192 & 3192 & & \\
\hline & $\mathrm{S}(-)$ & $\mathrm{S} 40$ & 0.009 & 0.009 & 0.003 & 0.003 & & \\
\hline & & $\mathrm{S} 135$ & $1.510^{-4}$ & $1.210^{-4}$ & 0.009 & 0.008 & & \\
\hline \multirow[t]{4}{*}{ Variable Discharge } & $\mathrm{T}\left(\mathrm{m}^{2} / \mathrm{d}\right)$ & $\mathrm{S} 40$ & 1292 & 1290 & 1629 & 1630 & - & 1242 \\
\hline & & $\mathrm{S} 135$ & 3249 & 3249 & 2768 & 2750 & & \\
\hline & $\mathrm{S}(-)$ & $\mathrm{S} 40$ & 0.03 & 0.03 & 0.023 & 0.023 & & \\
\hline & & $\mathrm{S} 135$ & 0.002 & 0.002 & 0.03 & 0.03 & & \\
\hline
\end{tabular}

\subsubsection{Other Analytical Solutions}

To apply other analytical solutions, only the drawdown data logged in S40 were taken since the tidal signal in S135 makes it difficult to interpret the results.

A better fit is obtained with the curves proposed by Sakr (2001) than with the Theis method. The $s-\log t$ curve is included in those corresponding to an $\mathrm{r}_{\mathrm{w}} / \mathrm{L}$ of 1 and $2 \cdot 10^{-4}$. The value for $T=1540 \mathrm{~m}^{2} / \mathrm{d}$ is quite close to that obtained with the classic methods $\left(1460 \mathrm{~m}^{2} / \mathrm{d}\right)$. However, the result for $\mathrm{S}\left(2.7510^{-5}\right)$ is much lower than that obtained with the classic methods.

Applying the method proposed by Sen and Altunkaynak (2004), which considers a variable discharge rate, gives a $\mathrm{T}$ value of $1,040 \mathrm{~m}^{2} / \mathrm{d}$, which is lower than the $1460 \mathrm{~m}^{2} / \mathrm{d}$ calculated with the classic methods. However, this method could not be applied to calculate S. It may be that the method proposed by those authors is better applied to confined aquifers, in which the drawdowns related to the discharge flow are much greater than in unconfined aquifers such as this one.

Following the methodology of Chapuis et al. (2006), the $s$ resulting from subtracting $h_{0}$ (head with a tidal signal logged before pumping) from the $h$ measured during pumping still shows a fluctuating signal, indicating this method does not entirely clean up the tidal signal. The application of this methodology has two main problems. On one hand, Chapuis et al. (2006) consider a uniform tidal signal in the piezometric log even though that signal is usually very irregular (Fig. 2) since these fluctuations are also affected by factors such as wind, barometric pressure, and changes in aquifer recharge. It is consequently very difficult to find tidal signals of the same amplitude at different times. In addition, the superpositioning of the tidal signal unaffected by pumping $\left(\mathrm{h}_{0}\right)$ on the signal logged during pumping $(\mathrm{h})$ can yield apparent maxima and minima that falsify the resulting drawdowns in the subtraction.

Briefly, analytical solutions other than those proposed by Theis and Cooper-Jacob, considering variable density and a variable discharge, provide similar $\mathrm{T}$ values to those obtained with the classic methods. The solution proposed by Sen and Altunkaynak (2004) gives a T value $30 \%$ lower than that given by the classic methods, whereas the solution proposed by Sakr (2001) yields a $\mathrm{T}$ value that is $5 \%$ higher. In contrast, the results for the storage coefficient with these two analytical solutions are much lower or could not be adjusted. 


\subsection{Evaluation of Reliability of Theis and Cooper-Jacob Methods}

Figure 5 shows the drawdowns in nine check points in the seven scenarios simulated with numerical modelling, although there seem to be fewer lines as some coincide. It can be observed that the s logs are symmetrical in all cases. There is only a slight difference in case 7, where the tidal effect appears, which not surprisingly shows greater amplitude in points closer to the boundary in which the tidal fluctuation condition is applied.

In all cases except those including vertical heterogeneity (cases 5 and 7), the drawdowns recorded at depth coincide with those logged at the surface. In cases 5 and 7, there is agreement between the $s$ obtained at point 1 at depth and at the surface (R1 and RS1, L1 and LS1) because both are in layer 1 . The same does not occur for the points in position 2, where R2 and L2 are located in layer 2, and RS2 and LS2 are in layer 1. In points R2 and L2, the drawdowns trend differently than in the other cases, with a sharper drawdown at the start of pumping and a slowing of the drawdown after about one hour of pumping (Fig. 5).

Cases 2, 3, and 4 show very similar results to case 1 for the degree of impact of the different circumstances considered on the values of $s$.

Table 5 presents the data for $\mathrm{T}$ and $\mathrm{S}$ calculated from the drawdown data obtained by numerical modelling after one day of pumping in the different scenarios considered. Coinciding with the values noted in the $s-t$ graphs (Fig. 5), the T values calculated in scenarios 2, 3, 4,

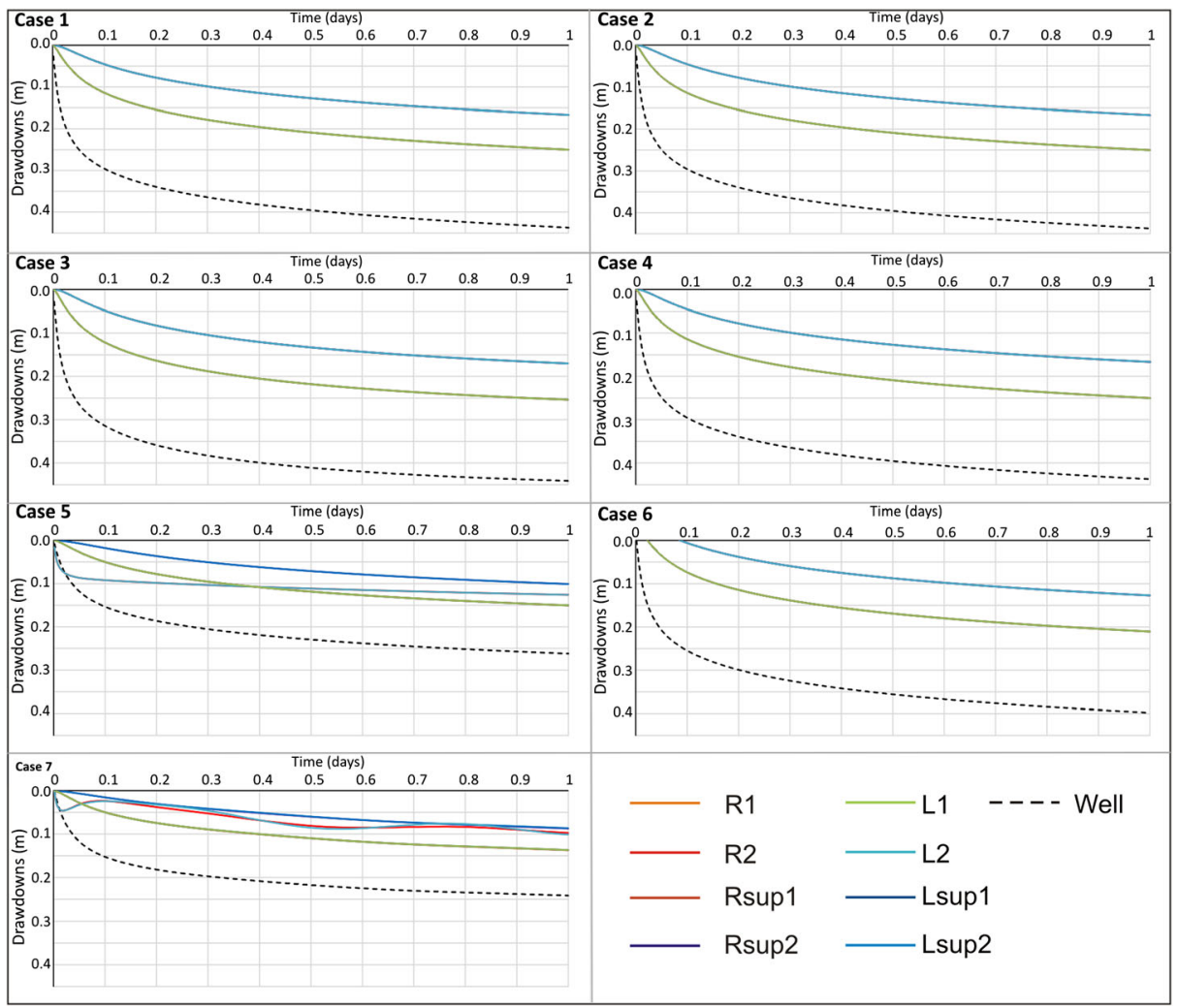

Fig. 5 Drawdowns versus time in the seven modelled cases at nine control points. Some lines are not visible as they are obscured by others than exactly coincide with them 


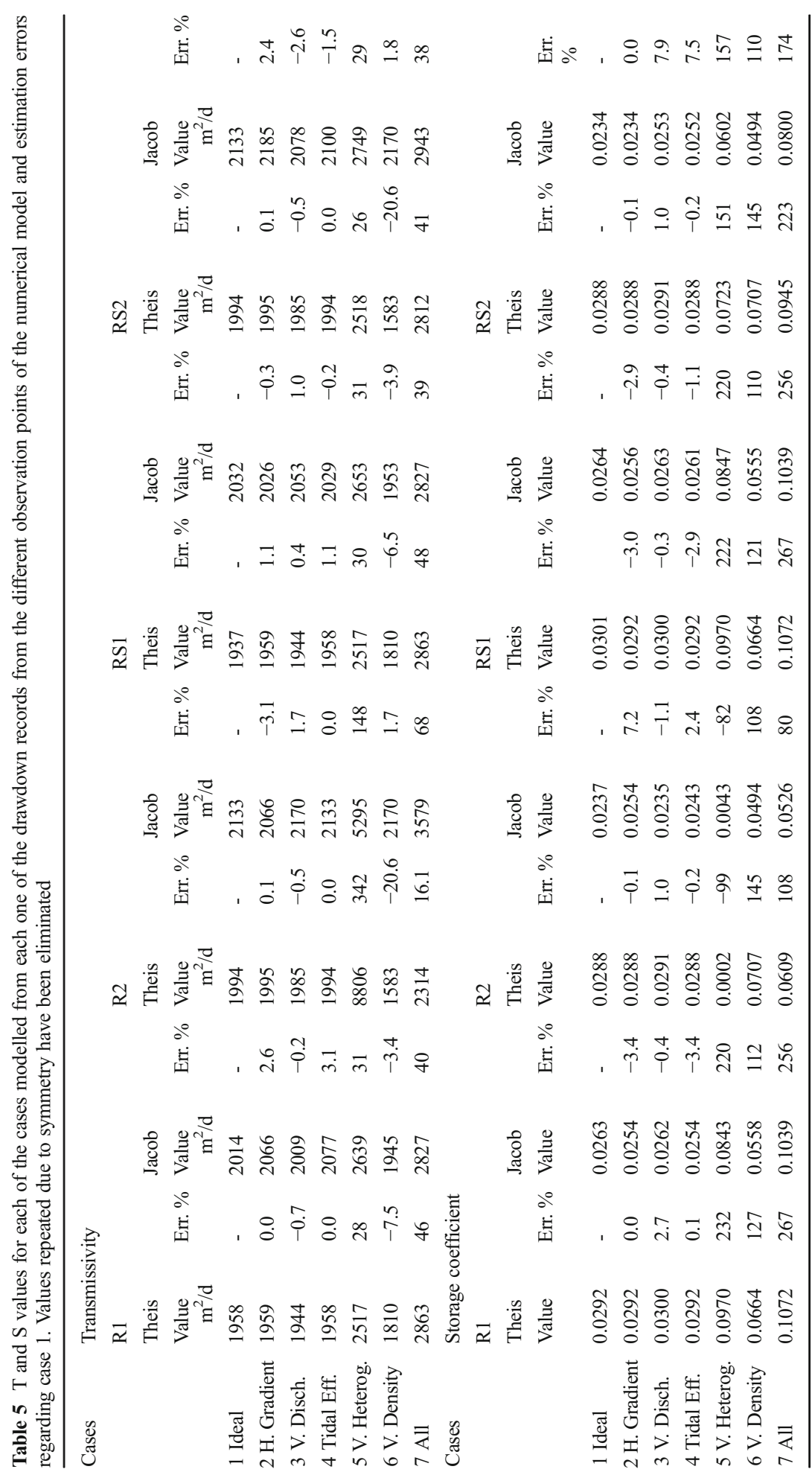


and 6 are quite similar to those obtained with the Theis and Cooper-Jacob methods (case 1). The error tends to be below $10 \%$, and only in the case of $s$ measured at the points farthest from the pumping point considering different densities (R2, RS2) does it reach an error of $20 \%$ (case 6).

Vertical heterogeneity is the most important factor impacting the applicability of classic methods in interpreting pumping tests. In that scenario (case 5), the $\mathrm{T}$ values obtained show a higher error percentage, although there is a great difference between the values calculated at the points located in layer 1 (R1, RS1, RS2), with errors of around $30 \%$, and the values in layer 2 (R2), with errors of over $100 \%$.

It is worth noting that, considering all the factors combined (case 7), the percentage of error drops down to $40-50 \%$ in most cases, probably because certain effects compensate for the effects of other factors.

The $\mathrm{S}$ is much more sensitive to changes with respect to the reference case. Acceptable results have only been found for cases taking into account a hydraulic gradient, variable withdrawal rate, and single-layer tidal effects (cases 2, 3, and 4), with errors generally under $3 \%$. In the other cases, the $\mathrm{S}$ values are much higher than the value calculated in case 1 , with errors of around 100-300\%.

As occurs with $\mathrm{T}$, the $\mathrm{S}$ values obtained for case 7 (in which all the variables are considered jointly) show a lower error than in case 5 . The fluid's variable density affects the estimation of $\mathrm{S}$ (errors of over $100 \%$ ) more than that of $\mathrm{T}$ (errors of $1.7-20.6 \%$ ).

\section{Discussion}

Applying the analytical solution proposed by Sen and Altunkaynak (2004) to the Motril-Salobreña aquifer to determine the effect of pumping with a variable discharge reveals a T value $28 \%$ lower than when estimated with the classic methods. In contrast, the results of the numerical modelling (case 3) considering a decrease of $10 \%$ in the pumping rate over the course of the test yielded a difference of less than $2.6 \%$ compared to the values from the Theis and Cooper-Jacob methods.

The other analytical solution applied in this work, proposed by Sakr (2001), considers the effect of two fluids of different density and yields $\mathrm{T}$ values $5 \%$ higher than the values of the classic methods for the Motril-Salobreña aquifer. In this case, in contrast, the results of the numerical modelling (case 6) indicate that this factor has more impact on the results and inversely to the form suggested by Sakr (2001), with T values up to $20 \%$ lower than those found with the classic methods.

When considering layers with different hydraulic conductivity (case 5), vertical flows occur that deform the equipotentials, losing their verticality. This occurs because the supply of water to the pumping well is proportional to the hydraulic conductivity and, therefore, is higher in layer 2, which has the highest K of the three. In fact, layer 2 supplied $71 \%$, layer $127 \%$, and layer $32 \%$ of the withdrawal volume. This causes a greater loss of head at the beginning in layer 2 and the appearance of a vertical hydraulic gradient from layers 1 and 3 towards layer 2 . This is why, in case 5, the drawdowns in L2 and R2 are much sharper at the start and gradually stabilize due to the supply of water from the other two layers.

Consequently, the $s$ values measured in the different layers do not correspond to the direct effect of the volume pumped and explains why they do not provide good results using the classic methods. Therefore, and in agreement with Alam and Olsthoorn (2014), the traditional methods tend to mask the effect in stratified aquifers with vertical flow. 
In case 5, it has been considered that the effect could be similar to what happens in a leaky confined aquifer, and we therefore opted to use the analytical solution proposed by Hantush (1960). The resulting T values are closer than with traditional methods, but the errors are still quite large (around $100 \%$ ).

The effect of tidal fluctuations on drawdowns is minimal when only one layer is considered (case 4 in Fig. 5), but is notable when several layers are taken into account (case 7 in Fig. 5). Specifically, the $s$ logged in the shallower points (R1, L1) show no fluctuation; however, deeper points (R2, L2) do show a clear effect of tidal fluctuations. This circumstance is in agreement with the effect found in the two monitoring wells for the Motril-Salobreña aquifer (S40 and S135), where a much sharper tidal fluctuation is found in the deeper piezometer (Fig. 2).

\section{Conclusions}

Synthetic numerical modelling has shown that estimating the transmissivity values and the storage coefficient calculated by Theis and Cooper-Jacob in a detrital aquifer can yield an error of under $10 \%$ when there is regional flow (hydraulic gradient), when the volume pumped varies up to $10 \%$ throughout the test, and when the levels show a tidal effect on the order of $1 \%$ of the total head.

A saltwater-freshwater interface can cause an error of $20 \%$ in the transmissivity results and of over $100 \%$ in the storage coefficient.

Vertical heterogeneity causes the greatest errors in the T and S results using classic methods. Layers with variations in hydraulic conductivity of $1-30 \mathrm{~m} / \mathrm{d}$ produce errors in both parameters of over $100 \%$.

The Theis and Cooper-Jacob methods can be applied in coastal aquifers to interpret pumping tests and obtain $\mathrm{T}$ and $\mathrm{S}$ values as long as the aquifers are uniform, without significant vertical heterogeneity, and in a sector without variable density (saline wedge).

If the Theis or Cooper-Jacob methods are used in stratified aquifers with variable vertical hydraulic conductivity or in which pumping is carried out in the saline wedge, the $\mathrm{S}$ data cannot be considered valid and the $\mathrm{T}$ values should be viewed as approximate and over-estimated.

In the specific case of the Motril-Salobreña aquifer, in fact, the $\mathrm{T}$ value $\left(1460 \mathrm{~m}^{2} / \mathrm{d}\right)$ obtained from applying the Theis and Cooper-Jacob methods on the pumping tests is probably overestimated as well. The storage coefficient value is uncertain and other methods will need to be used to determine it.

Acknowledgments This research has been financed by Project CGL2012-32892 (Ministerio de Economía y Competitividad of Spain) and by the Research Group Sedimentary Geology and Groundwater (RNM-369) of the Junta de Andalucía. Christine Laurin is thanked for the English version of the text.

Open Access This article is distributed under the terms of the Creative Commons Attribution 4.0 International License (http://creativecommons.org/licenses/by/4.0/), which permits unrestricted use, distribution, and reproduction in any medium, provided you give appropriate credit to the original author(s) and the source, provide a link to the Creative Commons license, and indicate if changes were made. 


\section{References}

Alam N, Olsthoorn TN (2014) Multidepth pumping tests in deep aquifers. Groundwater 52:148-160. doi:10. 1111/gwat.12155

Barlow PM, Masterson JP, Walter DA (1996) Hydrogeology and analysis of ground-water-flow system, sagamore marsh area, Southern Massachusetts USGS Water-Resources Investigations Report 96-4200

Boulton NS (1954) The drawdown of the water-table under non-steady conditions near a pumped well in an unconfined formation. Proc Inst Civil Eng 3:564-579

Calvache ML, Duque C, Gomez-Fontalva JM, Crespo F (2011) Processes affecting groundwater temperature patterns in a coastal aquifer. Int J Environ Sci Technol 8(2):223-236

Calvache ML, Ibáñez SP, Duque C, et al. (2009) Numerical modelling of the potential effects of a dam on a coastal aquifer in S. Spain. Hydrol Process 23:1268-1281

Capuano RM, Jan RZ (1996) In situ hydraulic conductivity of clay and silty-clay fluvial-deltaic sediments, Texas gulf coast. Ground Water 34:545-551. doi:10.1111/j.1745-6584.1996.tb2036.x

Chachadi AG, Gawas PD (2012) Correlation study between geoelectrical and aquifer parameters in West coast laterites. Int J Earth Sci Eng 5(2):282-287

Chapuis RP, Belanger C, Chenaf D (2006) Pumping test in a confined aquifer under tidal influence. Groundwater 44(2):300-305

Chattopadhyay PB, Vedanti N, Singh VS (2014) A conceptual numerical model to simulate aquifer parameters. Water Resour Manag 29:771-784. doi:10.1007/s11269-014-0841-6

Chen C, Jiao JJ (1999) Numerical simulation of pumping tests in multilayer well with non-darcian flow in the well-bore. Ground Water 37(3):465-474

Chen F, Wiese B, Zhou Q, Kowalsky MB, Norden B, Kempka T, Birkholzer JT (2014) Numerical modeling of the pumping tests at the ketzin pilot site for $\mathrm{CO}_{2}$ injection: model calibration and heterogeneity effects. Int $\mathrm{J}$ Greenh Gas Con 22:200-212

Cooper HH, Jacob CE (1946) A generalized graphical method for evaluating formation constants and summarizing well field history. Trans Am Geophys Union 27:526-534

Diamantopoulou P, Voudouris K (2008) Optimization of water resources management using SWOT analysis: the case of Zakynthos island, Ionian sea, Greece. Environ Geol 54(1):197-211

Doulgeris C, Zissis T (2014) 3D variable density flow simulation to evaluate pumping schemes in coastal aquifers. Water Resour Manag 28(4):4943-4956

Duffield GM (2007) AQTESOLV for Vindows, Version 4.5, HydroSOLVE Inc, Reston, Virginia

Duque C (2009) Influencia antrópica sobre la hidrogeología del acuífero Motril-Salobreña [Anthropogenic influence on the hydrogeology of the Motril-Salobreña Aquifer. $\mathrm{PhD}$ Thesis, University of Granada

Duque C, Calvache ML, Pedrera A, Martín-Rosales W, López-Chicano M (2008) Combined time domain electromagnetic soundings and gravimetry to determine marine intrusion in a detrital coastal aquifer (southern Spain). J Hydrol 349(3-4):536-547

Duque C, López-Chicano M, Calvache ML, Martin-Rosales W, Gómez-Fontalva JM, Crespo F (2011) Recharge sources and hydrogeological effects of irrigation and an influent river identified by stable isotopes in the motril-salobreña aquifer (southern Spain). Hydrol Process 25(4):2261-2274

Glover RE (1959) The pattern of fresh-water flow in a coastal aquifer. J Geophys Res 64(4):457-459

Hantush MS (1960) Modification of the theory of leaky aquifers. J Geophys Res 65(11):3713-3725

Hantush MS (1961) Aquifer test in partially penetrating wells. J Hyd Div, Proc Am Soc Civil Eng 87:171-194

Hemker CJ (1985) Transient well flow in a leaky multiple-aquifer systems. J Hydrol 81:111-126

Hemker CJ (1999) Transient well flow in vertically heterogeneous aquifers. J Hydrol 225:1-18

Hemker CJ, Maas C (1987) Unsteady flow to wells in layered and fissured aquifer systems. J Hydrol 90:231-249

Jacob CE, Lohman SW (1952) Non steady flow to a well of constant drawdown in an extensive aquifer. Trans Am Geophys Union 33(4):559-569

Keith JH, Willis DW, Robert PS (2006) Interpretation of transmissivity estimates from single-well pumping aquifer tests. Groundwater 44(3):467-471

Kohout FA (1964) The flow of fresh water and salt water in the Biscayne aquifer of the Miami area, Florida. In: sea water in coastal aquifers: U.S. Geological Survey Water-Supply Paper 1613-C:12-32

Kollet J, Zlotnik VA (2005) Influence of aquifer heterogeneity and return flow on pumping test data interpretation. J Hydrol 300(1-4):267-285. doi:10.1016/j.jhydrol.2004.06.011

Kourakos G, Mantoglou A (2011) Simulation and multi-objective management of coastal aquifers in semi-arid regions. Water Resour Manag 25(4):1063-1074

Lai RY, Karadi GM, Williams RA (1973) Drawdown at time-dependent flowrate. Water Resour Bull 9(5):892900

Lee BS, Song SH, Kim JS, Um JY, Nam K (2014) Availability of coastal groundwater discharge as an alternative water resource in a large-scale reclaimed land, Korea. Environ Earth Sci 71(4):1521-1532 
Maas C (1987a) Groundwater flow to a well in a layered porous medium 1. Steady flow. Water Resour Res 23: $1675-1681$

Maas C (1987b) Groundwater flow to a well in a layered porous medium 2. Nonsteady multiple-aquifer flow. Water Resour Res 23:1683-1688

Mastrocicco M, Sbarbati C, Colombani N, Petitta M (2013) Efficiency verification of a horizontal flow barrier via flowmeter tests and multilevel sampling. Hydrol Process 27:2414-2421

Mishra PK, Vessilinov V, Gupta H (2013) On simulation and analysis of variable-rate pumping tests. Groundwater 51(3):469-473

Moench AF (1995) Combining the neuman and boulton models for flow to a well in an unconfined aquifer. Groundwater 33:378-384

Moench AF (1996) Flow to a well in a water-table aquifer: an improved Laplace transform solution. Groundwater 34:593-596

Mohanty S, Jha MK, Kumar A, Jena SK (2012) Hydrologic and hydrogeologic characterization of a deltaic aquifer system in Orissa, eastern India. Water Resour Manag 26:1899-1928. doi:10.1007/s11269-012-9993-4

Neuman SP (1972) Theory of flow in unconfined aquifers considering delayed response of the water table. Water Resour Res 8(4):1031-1045

Neuman SP (1974) Effects of partial penetration on flow in unconfined aquifers considering delayed aquifer response. Water Resour Res 10(2):303-312

Ni JC, Cheng WC, Ge L (2011) A case history of field pumping tests in a deep gravel formation in the Taipei basin, Taiwan. Eng Geol 117:17-28. doi:10.1013/j.enggeo.2010.10.001

Papadopulos IS, Cooper HH (1967) Drawdown in a well of large diameter. Water Resour Res 3:241-244

Park HY, Jang K, Ju JW, Yeo JW (2012) Hydrogeological characterization of seawater intrusion in tidally-forced coastal fractured bedrock aquifer. J Hydrol 446-447:77-89

Riva M, Guadagnini A, Neuman SP, Franzetti S (2001) Radial flow in a bounded randomly heterogeneous aquifer. Transp Porous Media 45(1):139-193

Sabtan AA, Shehata WM (2003) Hydrogeology of Al-lith sabkha, Saudi Arabia. J Asian Earth Sci 21(4):423429

Sakr SA (2001) Type curves for pumping test analysis in coastal aquifers. Ground Water 39(1):5-9

Sen Z, Altunkaynak A (2004) Variable discharge type curve solutions for confined aquifers. J Am Water Resour Assoc Res 40(5):1189-1196

Sternberg YM (1967) Transmissibility determination from variable discharge pumping tests. Groundwater 5(4): $27-29$

Streltsova TD (1988) Well testing in heterogeneous formations. John Willey \& sons, New York

Thiem G (1906) Hydrologische methoden. Gebhardt, Leipzig

Theis CV (1935) The relation between the lowering of the piezometric surface and the rate and duration of discharge of well using groundwater storage. Trans Am Geophys Union 2:519-524

Trefry MG, Johnston CD (1998) Pumping test analysis for a tidally forced aquifer. Groundwater 36(3):427-433

Vouillamoz JM, Chatenoux B, Mathieu F, Baltassat JM, Legchenko A (2006) Efficiency of joint use of MRS and VES to characterize coastal aquifer in Myanmar. J Appl Geophys 61:142-154

Zekri S, Triki C, Al-Maktoumi A, Bazargan-Lari MR (2015) An optimization-simulation approach for groundwater abstraction under recharge uncertainty. Water Resour Manag 29:3681-3695. doi:10.1007/s11269-0151023-X

Zhang G (2013) Type curve and numerical solutions for estimation os transmisivity and storage coefficient with variable discharge condition. J Hydrol 476:345-351 